\title{
The Clinical Effectiveness of Chokeberry: A Systematic Review
}

\begin{tabular}{|r|l|}
\hline Journal: & Phytotherapy Research \\
\hline Manuscript ID: & PTR-10-0356 \\
\hline Wiley - Manuscript type: & Review \\
\hline Author: & 31 -Mar-2010 \\
\hline Complete List of Authors: & $\begin{array}{l}\text { Chrubasik, Cosima; Braun School of Public Health, The Hebrew } \\
\text { University-Hadassah Medical School } \\
\text { Li, George; Sydney University, Herbal Medicines Research and } \\
\text { Education Center } \\
\text { Chrubasik, Sigrun; Institute of Forensic Medicine, University of } \\
\text { Freiburg im Breisgau }\end{array}$ \\
\hline Keyword: & \begin{tabular}{l} 
Chokeberry, Aronia melanocarpa, systematic review, clinical trials \\
\hline
\end{tabular} \\
\hline
\end{tabular}

\section{s) ScholarONE \\ Manuscript Central}


1

2

3

4

5

6

7

8

9

10

11

\title{
The Clinical Effectiveness of Chokeberry-: A Systematic Review
}

\author{
C. Chrubasik ${ }^{1}$, G. Li $^{2}$, S. Chrubasik ${ }^{2,3}$ \\ ${ }^{1}$ Braun School of Public Health, Hadassah Medical Center, Hebrew University, Jerusalem, \\ Israel \\ ${ }^{2}$ Herbal Medicines Research and Education Centre, Faculty of Pharmacy, University of \\ Sydney, NSW 2006, Australia \\ ${ }^{3}$ Institute of Forensic Medicine, University of Freiburg, Freiburg, Germany
}

\section{Correspondence and requests for reprints to}

Dr. Cosima Chrubasik

Braun School of Public Health

The Hebrew University-Hadassah Medical School

POB 12272, Jerusalem, 91120

Israel

Eamil: chrubasik@gmail.com 


\begin{abstract}
Products derived from the black chokeberry, Aronia melanocarpa, are claimed to be beneficial in disorders or diseases associated with oxidative stress. The claims are based on evidence from in vitro studies and animal experiments. The active principle - a mixture of procyanidins, anthocyanins and phenolic acids - constitutes one of the most potent natural antioxidants. We carried out a systematic review of the quality of the clinical trials on chokeberry products that had been published up to December 2009, and used conventionally established criteria to assess the strength of the evidence for their clinical effectiveness. Thirteen studies were identified. The quality of most of the trials and, correspondingly, the evidence of effectiveness for Aronia products is poor. Though laboratory and clinical data indicate that chokeberry products may well be useful as "functional food" for disorders or diseases related to oxidative stress, these promising indications need to be confirmed in more rigorous studies before putative therapeutic uses can be confidently recommended for chokeberry products.
\end{abstract}

\title{
Key words
}

Chokeberry, Aronia melanocarpa, systematic review, clinical trials, anti-oxidative effect 


\section{Phytotherapy Research}

\section{INTRODUCTION}

The black chokeberry, Aronia melanocarpa (Family- Rosaceae) is native to North America and Canada and was introduced into Europe about a century ago. Because of the astringent taste of the raw berries and their smell of bitter-almonds, pure Aronia products are not particularly popular, although they have been documented as a "functional food" in Russia since the 1940s. Chokeberry juice has been used primarily for blending with other juices or in the preparation of syrups, jellies, teas, liqueurs, spirits and fruit wine. The interest in Aronia products has recently increased, not only because of the putative health-promoting effects of Aronia, but also because the plant is pest-resistant and easy to cultivate (http://opus.haw-hamburg.de/volltexte/2008/513/pdf/med_y_210.pdf). Laboratory reports of potentially useful activities began to appear in the mid 1990s, and these have been accompanied since 2000 by a modest number of reports of its use in a variety of clinical settings.

Chokeberries have a greater content of phenolic constituents than most of the other black berries (Kahkönen et al., 2001, Wu et al., 2004). These comprise procyanidins, anthocyanins and phenolic acids, and the amounts reflect antioxidative potency in laboratory testing (Zheng and Wang, 2003). Procyanidins and some anthocyanins may also form complexes with free iron and copper, which catalyse free-radical reactions and contribute to the reduction in pro-oxidative activity seen with Aronia products (Hider et al., 2001). Popular health claims for Aronia products are that they: (i) combat heart disease and other cardiovascular problems, (ii) mitigate hypertension, (iii) maintain a healthy urinary tract, (iv) fight against bacteria and viruses, (v) strengthen memory, (vi) aid digestion and (vii) help to decrease the amount of cholesterol carried as Low Density Lipoproteins (LDP) www.associatedcontent.com/article/870111/10_benefits_of_aronia_berry.html?cat=51). Additional claims by association have been made in diabetes and arthritis (www.doverpost.com/lifestyle/x124604982/Studies-show-aronia-berries-may-be-full-of- 
health-benefits), as well as in cancer (http://hubpages.com/hub/aronia). These claims are primarily based on research with other black berry products or isolated anthocyanins (ZafraStone et al., 2007) or are transferred from in vitro and experimental studies with chokeberry preparations (Kulling et al., 2008).

The aim of this systematic review is to evaluate the current clinical evidence for effectiveness of chokeberry preparations.

\section{METHODS}

We searched several electronic databases: Medline/ OVID, Silverplatter, and CENTRAL from 1950 up to December 2009, using some or all of the search terms: chokeberry, Aronia, Aronia melanocarpa and searched by hand for publications not stored electronically (eg: theses, webpages). Two authors (CC and SC) extracted the data independently and evaluated the quality of the studies and the strength of the evidence of clinical effectiveness using the same criteria as in previous reviews (Chrubasik et al., 2004, Gagnier et al., 2004, Chrubasik et al., 2006, 2007a,b, 2008, Vlachojannis et al., 2009, 2010a,b).

Briefly, the assessment of quality was based on "yes" or "no" answers to the following questions (to the extent that they were applicable in the context of each study):

Was or were -

(i) patients included on the basis of specified eligibility criteria;

(ii) randomization appropriate;

(iii) treatment allocation concealed;

(iv) baseline values of the groups similar

(v) outcome measures and control interventions explicitly described;

(vi) co-interventions comparable;

(vii) outcome measures relevant;

(viii) adverse events fully described; 


\section{Phytotherapy Research}

5

(ix) attrition of patients from the study (the "drop-outs") fully described;

(x) sample size based on a priori power calculation;

(xi) in the event of attrition of patients during the study, analysis by intention-to-treat;

(xii) point estimates and measures of variability presented for the primary outcome measure; (xiii) studies undertaken over an appropriate time-course to demonstrate the putative effect Clearly, for some studies, particularly simple observational studies, some of the questions are not applicable but the inability to supply a "yes" answer is, in itself, a marker of "absence of quality" in systematic reviews of this sort.

Disagreements between the assessors over these deliberately simplified questions were few (arising mostly from lack of transparency in describing methods) and were resolved after discussion. Adding up the "yes" answers applicable to each study gave it a Total Score (TS) out of a maximum of 13. The distribution of Total scores for the studies in the review is one way to indicate the strength of evidence of effectiveness from a group of individual studies. Early in the history of the clinical investigation of a particular product, most of the studies will be "exploratory" in that they determine the conditions, study design, and sample size needed in planning to maximise the chances of demonstrating useful clinical effects in later "confirmatory" studies.

A conventional way of assessing evidence of clinical effectiveness from a more mature body of work is to define the evidence as "strong", "medium" or "weak", according to the following criteria: (i) "strong" - pooling of data from at least 2 confirmatory studies demonstrating a clinically relevant effect; (ii) "moderate" - consistent findings from one confirmatory study with a clinically relevant effect, multiple exploratory studies of high internal validity, or both; (iii) poor - multiple exploratory studies of low internal validity or a single study of high internal validity. 


\section{RESULTS}

Thirteen clinical trials were identified. They have been assigned a number from 1 to 13 in chronological order, to facilitate reference between the tables and the text. Table 1 gives some characteristics of the publications in which the studies appeared, and the general setting. Nine papers/abstracts were in English and the remaining 4 in Polish. In 8 papers (numbers 4,5,711,13), the setting was either the "metabolic syndrome (papers 7,9,11) - a constellation of features under the general headings: abdominal obesity, atherogenic dyslipidaemia, hypertension, insulin resistance, and prothrombotic and pro-inflammatory state - or conditions presenting with a single or limited selection of those features (papers $4,5,8,10,13$ ). Three of the remaining 5 studies (papers 1-3) investigated effects of Aronia in other conditions with increased oxidative stress, and the other 2 (papers 6 and 12) were of the effects of Aronia on the antioxidant capacity in healthy volunteers (Table 1).

Table 2 gives some indication of how the studies were carried out. Five studies (papers 5, 7 , $10,12,13$ ) had only one group, 2 being simple observational studies of effects of giving an Aronia product (paper 5 and 7), and the rest incorporating a formal, single or double crossover, either to a placebo or no treatment $\left(10,{ }_{2} 12_{2}-13\right)$. The remaining studies were comparisons between an "Aronia" group (receiving an Aronia product) and either a "Placebo" group (receiving a placebo) or a "Control” group of patients receiving nothing (papers 3,_4,_6, $8,9,11)$ or healthy subjects receiving nothing $(1,2)$.

In 7 studies (papers 1,2, 5, 7-9, 11) the Aronia product was Aronox ${ }^{\mathrm{R}}$, prepared from the berries, not by a solvent extraction, but by purification on chromatographic bed, drying and vaporization (annaskoc@ak.am.wroc.pl), and standardised in $100 \mathrm{mg}$ tablets each containing $15 \mathrm{mg}$ of anthrocyanins. In the remaining papers, the Aronia product consisted of juices with varying anthrocyanin contents (Table 1). We tried unsuccessfully to contact Dr. Naruszewicz by phone and email (marek.naruszewicz@wum.edu.pl), in an attempt to clarify how and why 
he appears to have used three $85 \mathrm{mg}$ tablets of $\operatorname{Aronox}^{\mathrm{R}}$ per day as his study medication although Aronox tablets contain a $100 \mathrm{mg}$ dose of dried juice.

The duration of the studies ranged from 2 hours to 3 months, with most lasting between 4 and 8 weeks. In almost all of the studies, there was a striking multiplicity in the measurements undertaken as potential outcome measures - indicating a strong "exploratory" trust to those studies. The use of the Aronia product was associated, in every study, with a favourable change in at least one or more of the measurements that had been undertaken (Table 3).

Table 4 shows the responses to the questions by which the quality of each study was assessed. All scored at least 4 "yeses", for questions (i), (v), (vii) and (xiii) but, although all outcomes were explicitly described and relevant to the condition under study, there is no transparency as to whether any single outcome had been pre-specified for the purposes of hypothesis testing and a priori planning of sample size as would be required for a study to be considered "confirmatory" rather than "exploratory" as defined in the Methods. Thus, although the collection of 10 studies centring on the metabolic syndrome and aspects thereof produced generally consistent favourable results for the chosen Aronia product, the collection does not include even a single "confirmatory" study, so that the overall strength of evidence, in even this reasonably coherent body of work, must be classified as "poor" by the criteria outlined in the Methods section. Besides the lack of transparency over advance stipulation of a critical outcome measure, only one study (paper 12) gave any adequate account of adverse events and only one gave adequate account of attrition (paper 8, in which the attrition was zero!). Attrition needs to be considered in relation to whether the results should be analysed per protocol or by intention to treat). Nonetheless, an encouraging feature of Table 3 is the trend towards improved study quality over the 9 years for which the Aronia products have been studied. 


\title{
DISCUSSION
}

\begin{abstract}
Although the limited body of work up to December 2009 presents evidence of clinical effectiveness which must be classified as "poor" by conventional criteria, it is by no means unpromising. However, for the products to gain the acceptance that they may well deserve, a new generation of "confirmatory" studies needs to be planned and undertaken. The evidence from laboratory investigations (reviewed recently, for example, by (Kullig and Rawel, 2008), as well as the clinical studies covered in this review provide potentially valuable pointers for the planning process. The laboratory investigations consist of product stability studies and studies, in animal models and cell lines of various areas of potential benefit and toxicity, and dose finding.
\end{abstract}

Product stability studies. The rate of degradation of anthocyanins is affected by type of anthocyanidin, the amount of glycosylated sugar and the care taken to reduce contact with air (specifically oxygen) during preparation before packaging in bottles or cartons (Kaack and Austed, 1998), and during storage (the degradation of total anthocyanins has been shown to be $22 \%$ faster in cartons, for example, than in glass bottles (Trost et al., 2008).

Vitamin C can reduce the oxidative degradation of the anthocyanins (Kaack and Austed, 1998) and the near black anthrocyanidin-containing juices are often presented as dilutions other fruit juice, e.g. lemon juice. The in vitro antioxidant activity of a lemon juice mixture was twice as high when pure lemon juice was enriched with 5\% of Aronia concentrate (González-Molina et al., 2008). Dilutions of Aronia juice in lemon juice have an attractive red colour that depends on a mixture of glycosylated and non-glycosylated anthocyanins (aglycones). The ranking order of individual non-glycosylated anthocyanins in a blueberryaronia nectar (from the most to least stable) was as follows: cyanindin > peonidin > petunidin $>$ malvidin $=$ delphinidin. For the glycosylated anthocyanins, the sugar with which the anthocyanidin is glycosylated makes a difference, degradation rate being least with glucose 


\section{Laboratory studies indicating potential benefits of Aronia or anthrocyanins}

The earliest documented laboratory demonstration of a potentially useful action of Aronia was an anti-inflammatory effect shown in 1994 by Borissova and co-workers. Aronia anthocyanins were more effective than rutin in suppressing inflammation in the rat paw oedema test. More recently, a potent anti-inflammatory effect of a proprietary extract of Aronia was demonstrated in endotoxin-induced uveitis in rats (Ohgami et al., 2005). After 24 hours, the number of inflammatory cells, the protein concentrations, and the levels of NO, PGE2, and TNF-alpha in aqueous humour from both eyes were dose-dependently decreased. The anti-inflammatory effect of $100 \mathrm{mg}$ of Aronia extract was as strong as that of $10 \mathrm{mg}$ of prednisolone and stronger than that of either anthocyanin or quercetin, another component of the extract, when given alone. The same extract also dose-dependently suppressed LPSinduced nitric oxide synthase and COX-2 protein expressions in a mouse macrophage cell 
line, indicating that it acts in pathways that involve several inflammatory mediators (Ohgami et al., 2005).

In 1995, Niedworok et al described protection against damage from cyclophosphamide" and radiation disease (1995 theses quoted in Niedworok's review;

bdb.trzcianka.com.pl/oferujemy/Aronox badania/ANG/Table I-25_eng.pdf).

Another early demonstration of potential benefit was by Atanasova-Goranova et al. in 1997. Their study in rats showed a hepatoprotective effect: Aronia nectar (fruit juice and pulp from the black chokeberry) inhibited nitrosamine production induced by aminopyrin and sodium nitrite in rats with a concomitant reduction in organic liver damage. Aronia juice also showed a hepatoprotective effect when given as a pre-treatment in a rat model of hepatotoxicity (Valcheva-Kuzmanova et al., 2004 and 2006). The juice prevented the carbon tetrachlorideinduced increase in transaminase activities, and also the elevation of plasma and liver malondialdehyde.

Since these early demonstration of tissue and cellular, there have been many others. Two studies revealed some antimutagenic potential of Aronia extract or its anthocyanin ingredients (Gasiorowski et al., 1997; Gasiorowski and Brokos, 2001). Rats treated with the colonic carcinogen "azoxymethane" and fed a diet with Aronia extract (385 mg of anthocyanins and $1645 \mathrm{mg}$ of total phenolics per $\mathrm{g}$ of diet) had fewer foci of aberrant colonic cryptscolonic aberrant crypt foci and less proliferation of colonic cells, suggesting that anthocyanin-rich aronia extracts may offer some protect against colonic cancer (Lala et al., 2006). However, although force feeding of rats with $8 \mathrm{ml} / \mathrm{kg}$ of chokeberry juice for 28 days was apparently harmless, doing so in combination with the chemical carcinogen, N-nitrosodiethylamine, caused more toxicity and DNA damage than the carcinogen alone (Krajka-Kuźniak et al., 2009). 
Matsumoto et al., 2004 demonstrated a gastro-protective effect of a methanolic extract of Aronia (DER 1:10) that as effective as that of quercetin and was caused by the red pigment fraction of the extract. In a rat model in which gastric ulcers were induced by indomethacin, a significant reduction of the depth and severity of mucosal lesions was found when Aronia juice was given concomitantly with the indomethacin (Valcheva-Kuzmanova et al., 2005). Isolated Aronia anthocyanins have also been shown in rats to mitigate the effects of poisoning by lead (Kowalczyk et al., 2002) and cadmium (Kowalczyk et al., 2005).

Several in-vitro studies, one open study in chimpanzes and two exploratory studies in humans have suggested that an aqueous elderberry extract may have a place in the treatment of viral infections including the pandemic ones (Vlachijannis et al., 2010). Black chokeberries contain even more anthocyanins than do elderberries (Wu et al. 2004), and an in vitro study has 
shown that Aronia juice inhibited the reproduction of Influenza virus in its initial stages.

Thus, proprietary standardized Aronia products may possibly have some use as anti-influenza preparations. (http://www.antibiotikamonitor.at/34 03/34_03 $\quad 1 \quad 04 . h t m)$.

Such an extraordinary multiciplicity of effects claimed for Aronia has suggested to many researchers and practitioners that the Aronia products affect very basic cellular processes that are common to its many putative effects - namely effects that reduce the pathological generation of oxygen free radicals and/or promote scavenging of oxygen free radicals (Kulling et al., 2008).

Safety: The Polish company Agropharm in Lodz has some unpublished data showing that intragastric administration of up to $5 \mathrm{~g} / \mathrm{kg}$ of Aronia anthocyanins was not associated with any toxic symptoms in mice. Likewise, giving $10 \mathrm{mg} / \mathrm{kg}$ of anthocyanins for 6 weeks was well tolerated and the internal organs did not show any histological changes

(http://bdb.trzcianka.com.pl/oferujemy/Aronox\%20badania/ANG/Table\%20I-25_eng.pdf). Nonetheless, the observations of (Krajka-Kuźniak et al., 2009) indicate that some attention needs to be given to the possibility that Aronia products and related substances may act synergistically with other foodstuffs, medicines, poisons, chemotherapeutic agents, etc., that may be relevant in patients for whom in future Aronia products might otherwise be indicated.

\section{Pointers to planning "confirmatory" clinical studies}

Setting: The metabolic syndrome and related disorders seem to be a promising target population to be studied, in that the conditions are prevalent, and increasingly so. Finding suitable subjects to study will be relatively easy and any demonstrated benefits are likely to reduce, not only the morbidity and mortality of the conditions, but also their enormous financial effects. The same might be said of endemic viral diseases such as influenza. 
Dose: Doses do of course need to be tailored to the target populations to be investigated, but current empirical experience suggests that the daily dose of Aronia product should contain 300 - $600 \mathrm{mg}$ of anthocyanins - considerably more than in the clinical studies reviewed here (http://bdb.trzcianka.com.pl/oferujemy/Aronox\%20badania/ANG/Table\%20I-25_eng.pdf). If the doses used in animal studies are extrapolated to humans, the daily dose would correspond to an anthocyanin content of 1600 to $3000 \mathrm{mg}$ contained in about $700-1400 \mathrm{ml}$ juice per day (see below). Considerations of dose need to take into account considerations of how different Aronia products are manufactured and stored (see above - Product stability)

Adverse reactions: Considerations of dose also need to be tempered by considerations of possible adverse interactions with co-medications (see above), and for affects that may conceivably not have been studied fully in animals. Although no adverse events were reported in any of the clinical studies reviewed, squeezed Aronia juice may have mild diuretic and laxative effects from its potassium content and sorbitol-related laxative effects. Long-term use of Aronia preparations may conceivably cause anaemia because of the iron-chelating effect of anthocyanins. Like other polyphenol-containing products, Aronia juice or concentrate can also cause superficial staining of the teeth stain (Shellis et al., 2005). As with almost any product containing molecules of sufficient size, hypersensitivity may occur, albeit rarely It is, of course mandatory that, for any adverse reactions that occur during any studies, a full description is provided, and a formal consideration of the likelihood that it is causally related to the product being studied. If subjects fail to complete the study because of adverse effects or any other reason, consideration of the possible effects of that attrition must be allowed for by comparing intention to treat and per protocol analyses of the results.

Outcome measures: Those used in the clinical trials reviewed to be reliable and relevant to improved well-being.

Duration: Short and medium term studies of biochemical and cytological measurements are needed as well as simple clinical measurements such as body weight and arterial blood 
14

pressure (as in Table 2) which are indications of potential benefit on terms of risk reduction.

Longer term studies are also required to_determine whether the potential risk reduction is

translatable into better clinical outcomes from disease, improved life expectancies and greater

confidence that the potential benefits are not offset by toxicity in the longer term

(www.fda.gov/cder/guidance/index.htm,

www.emea.europa.eu/pdfs/human/ich/030095en.pdf).

Feldfunktion geändert

In conclusion, there is appreciable experimental evidence of the effectiveness of Aronia

products in an extraordinary range of pathological conditions in which the underlying damage

is probably mediated by uncontrolled oxidative processes. The current evidence of

effectiveness in several clinical contexts is promising, but does not yet meet the accepted standards that would secure them an indisputable place in therapy. Fortunately, there are several promising avenues of investigation that may be pursued to remedy the present shortcomings.

\section{References}

Atanasova-Goranova VK, Dimova PI, Pevicharova GT. 1997. Effect of food products on endogenous generation of N-nitrosamines in rats. Br J Nutr 78:335-45.

Borissova P, Valcheva S, Belcheva A. 1994. Antiinflammatory effect of flavonoids in the natural juice from Aronia melanocarpa, rutin and rutin-magnesium complex on an experimental model of inflammation induced by histamine and serotonin. Acta Physiol Pharmacol Bulg 20:25-30.

Broncel M, Koziróg-Kołacińska M, Andryskowski G, Duchnowicz P, Koter-Michalak M, Owczarczyk A, Chojnowska-Jezierska J. 2007. [Effect of anthocyanins from Aronia 
melanocarpa on blood pressure, concentration of endothelin-1 and lipids in patients with metabolic syndrome]. Pol Merkur Lekarski 3:116-9.

Chrubasik S, Conradt C, Roufogalis B. 2004. Effectiveness of Harpagophytum extracts and clinical efficacy. Phytotherapy Res 18: 187-9.

Chrubasik C, Duke RK, Chrubasik S. 2006. The evidence for clinical efficacy of rose hip and seed: a systematic review. Phytother Res 20:1-3.

Chrubasik JE, Roufogalis BD, Wagner H, Chrubasik S. 2007a. A comprehensive review on nettle effect and efficacy profiles. Part I: Herba urticae. Phytomedicine 14:423-35.

Chrubasik JE, Roufogalis BD, Wagner H, Chrubasik S. 2007b. A comprehensive review on nettle effect and efficacy profiles. Part II: Urticae radix. Phytomedicine 14:568-79.

Chrubasik C, Roufogalis B, Müller-Ladner U, Chrubasik S. 2008. A systematic review on the Rosa canina effect and efficacy profiles. Phytother Res 22:725-33.

Gagnier JJ, Chrubasik S, Manheimer E. 2004. Harpgophytum procumbens for osteoarthritis and low back pain: A systematic review. BMC Complement Altern Med 4:13.

Gasiorowski K, Szyba K, Brokos B, Kołaczyńska B, Jankowiak-Włodarczyk M, Oszmiański J. 1997. Antimutagenic activity of anthocyanins isolated from Aronia melanocarpa fruits. Cancer Lett 119:37-46. 
16

Gasiorowski K, Brokos B. 2001. DNA repair of hydrogen peroxide-induced damage in human lymphocytes in the presence of four antimutagens. A study with alkaline single cell gel electrophoresis (comet assay). Cell Mol Biol Lett 6:897-911.

González-Molina E, Moreno DA, García-Viguera C. 2008. Aronia-enriched lemon juice: a new highly antioxidant beverage. J Agric Food Chem 56:11327-33.

Hider RC, Liu ZD, Khodr HH. 2001. Metal chelating of polyphenols In: Packer L, editor. Methods in enzymology, flavonoids and other polyphenols. Vol. 335, San Diego: Academic Press:190-203.

Jankowski A, Jankowska B, Niedworok J. 2000. [The influence of Aronia melanocapra in experimental pancreatitis]. Pol Merkur Lekarski 8:395-8.

Jensen GS, Wu X, Patterson KM, Barnes J, Carter SG, Scherwitz L, Beaman R, Endres JR, Schauss AG. 2008. In vitro and in vivo antioxidant and anti-inflammatory capacities of an antioxidant-rich fruit and berryjuice blend. Results of a pilot and randomized, double-blind, placebo-controlled, cross-over study. J Agricult Food Chem 56:8326-333.

Jurgoński A, Juśkiewicz J, Zduńczyk Z. 2008. Ingestion of black chokeberry fruit extract leads to intestinal and systemic changes in a rat model of prediabetes and hyperlipidemia. Plant Foods Hum Nutr 63:176-82.

Kaack K, Austedt T. Interaction of vitamin C and flavonoids in elderberry (Sambucus nigra L.) during juice processing. Plant Foods Human Nutr 1998;52:187-198. 
Kähkönen MP, Hopia AI, Heinonen M. 2001. Berry phenolics and their antioxidant activity. J Agric Food Chem 49:4076-82.

Kasparaviciene G, Briedis V. 2003. [Stability and antioxidant activity of black currant and black aronia berry juices]. Medicina (Kaunas) 39 Suppl 2:65-9.

Kowalczyk E, Jankowski A, Niedworok J, Smigielski J, Jankowska B. 2002

[The effect of anthocyanins from Aronii melanocarpa and acetylcysteine on selected aftereffects of lead acetate poisoning]. Pol Merkur Lekarski 12:221-3.

Kowalczyk E, Kopff A, Fijałkowski P, Kopff M, Niedworok J, Błaszczyk J, Kedziora J, Tyślerowicz P.2003. Effect of anthocyanins on selected biochemical parameters in rats exposed to cadmium. Acta Biochim Pol 50:543-8.

Kowalczyk E, Fijałkowski P, Kura M, Krzesiński P, Błaszczyk J, Kowalski J, Smigielski J, Rutkowski M, Kopff M. 2005. [The influence of anthocyanins from Aronia melanocarpa on selected parameters of oxidative stress and microelements contents in men with hypercholesterolemia]. Pol Merkur Lekarski 19:651-3.

Krajka-Kuźniak V, Szaefer H, Ignatowicz E, Adamska T, Oszmiański J, Baer-Dubowska W. 2009. Effect of Chokeberry (Aronia melanocarpa) juice on the metabolic activation and detoxication of carcinogenic N-nitrosodiethylamine in rat liver. J Agric Food Chem 57:50717.

Kulling SE, Rawel HM. 2008. Chokeberry (Aronia melanocarpa) - A review on the characteristic components and potential health effects. Planta Med. 74:1625-34. 
Lala G, Malik M, Zhao C, He J, Kwon Y, Giusti MM, Magnuson BA.2006. Anthocyaninrich extracts inhibit multiple biomarkers of colon cancer in rats. Nutr Cancer 54:84-93.

\begin{abstract}
Matsumoto M, Hara H, Chiji H, Kasai T. 2004. Gastroprotective effect of red pigments in black chokeberry fruit (Aronia melanocarpa Elliot) on acute gastric hemorrhagic lesions in rats. J Agric Food Chem 52:2226-9.
\end{abstract}

Naruszewicz M, Laniewska I, Millo B, Dłuzniewski M. 2007. Combination therapy of statin with flavonoids rich extract from chokeberry fruits enhanced reduction in cardiovascular risk markers in patients after myocardial infraction (MI). Atherosclerosis 194:e179-84.

\begin{abstract}
Naruszewicz M, Daniewski M, Laniewska I, Pikto-Pietkiewicz W, Millo B, Zapolska-
Downar D. 2003. Effect of anthocyanins from chokeberry (Aronia melanocarpa) on blood pressure, inflammatory mediators and cell adhesion molecules in patients with a history of myocardial infarction (MI). Atherosclerosis Suppl 4: 143.
\end{abstract}

\author{
Ohgami K, Ilieva I, Shiratori K, Koyama Y, Jin XH, Yoshida K, Kase S, Kitaichi N, Suzuki \\ Y, Tanaka T, Ohno S. 2005. Anti-inflammatory effects of aronia extract on rat endotoxin- \\ induced uveitis. Invest Ophthalmol Vis Sci 46:275-81.
}

\begin{abstract}
Pawlowicz, P. Wilczynski, J. Stachowiak, G. Hincz, P. 2007. [Administration of natural anthocyanins derived from chokeberry retardation of idiopathic and preeclamptic origin. Influence on metabolism of plasma oxidized lipoproteins: the role of autoantibodies to oxidized low density lipoproteins]. Ginekologia Polska 71:848-53.
\end{abstract}


Pawłowicz P, Stachowiak G, Bielak A, Wilczyński J. 2001. [Administration of natural anthocyanins derived from chokeberry (aronia melanocarpa) extract in the treatment of oligospermia in males with enhanced autoantibodies to oxidized low density lipoproteins (oLAB). The impact on fructose levels]. Ginekol Pol 72:983-8.

$+4842 / 2711124$

Pilaczynska-Szczesniak L, Skarpanska-Steinborn A, Deskur E, Basta P, HoroszkiewiczHassan M. 2005. The influence of chokeberry juice supplementation on the reduction of oxidative stress resulting from an incremental rowing ergometer exercise. Int J Sport Nutr Exerc Metab 15:48-58.

Poreba R, Skoczynska A, Gac P, Poreba M, Jedrychowska I, Affelska-Jercha A, Turczyn B, Wojakowska A, Oszmianski J, Andrzejak R. 2009. Drinking of chokeberry juice from the ecological farm Dzieciolowo and distensibility of brachial artery in men with mild hypercholesterolemia. Ann Agric Environ Med 16:305-8.

Shellis RP, Addy M, Rees GD.2005. In vitro studies on the effect of sodium tripolyphosphate on the interactions of stain and salivary protein with hydroxyapatite. J Dent 33:313-24.

Sikora JM, Kostka B, Kozirog-Kolacinska, Choinowska-Jezierska J, Mikiciuk-Olasik E, Broncel M. 2007. The influence of anthocyanins from Aronia melanocarpa on platelet aggregation in patients with metabolic syndrome. www.science24.com/paper/10824

Simeonov SB, Botushanov NP, Karahanian EB, Pavlova MB, Husianitis HK, Troev DM. 2002. Effects of Aronia melanocarpa juice as part of the dietary regimen in patients with diabetes mellitus. Folia Med (Plovdiv) 44:20-3. 
Skoczynska A, Jedrychowska I, Poreba R, Affelska-Jercha A, Turczyn B, Wojakowska A, Andrzejak R. 2007. Influence of chokeberry juice on arterial blood pressure and lipid parameters in men with mild hypercholesterolemia. Pharmacological Reports 59 Suppl 1:177-

82.

Trost K, Golc-Wondra A, Prosek M, Milivojevic L. 2008. Anthocyanin degradation of blueberry-aronia nectar in glass compared with carton during storage. J Food Sci 73:S405-11.

Valcheva-Kuzmanova S, Borisova P, Galunska B, Krasnaliev I, Belcheva A. 2004.

Hepatoprotective effect of the natural fruit juice from Aronia melanocarpa on carbon tetrachloride-induced acute liver damage in rats. Exp Toxicol Pathol 56:195-201.

Valcheva-Kuzmanova S, Marazova K, Krasnaliev I, Galunska B, Borisova P, Belcheva A. 2005. Effect of Aronia melanocarpa fruit juice on indomethacin-induced gastric mucosal damage and oxidative stress in rats. Exp Toxicol Pathol 56:385-92.

Valcheva-Kuzmanova SV, Popova PB, Galunska BT, Belcheva A. 2006. Protective effect of Aronia melanocarpa fruit juice pretreatment in a model of carbon tetrachloride-induced hepatotoxicity in rats. Folia Med (Plovdiv) 48:57-62.

Valcheva-Kuzmanova S, Kuzmanov K, Tancheva S, Belcheva A. 2007a. Hypoglycemic and hypolipidemic effects of Aronia melanocarpa fruit juice in streptozotocin-induced diabetic rats. Methods Find Exp Clin Pharmacol 29:101-5. 
Valcheva-Kuzmanova S, Kuzmanov K, Mihova V, Krasnaliev I, Borisova P, Belcheva A. 2007b. Antihyperlipidemic effect of Aronia melanocarpa fruit juice in rats fed a highcholesterol diet. Plant Foods Hum Nutr 62:19-24.

Valcheva-Kuzmanova S, Zhelyazkova-Savova M. 2009. Anxiolytic-like effect of Aronia melanocarpa fruit juice in rats. Methods Find Exp Clin Pharmacol 31:651-4.

Vlachojannis JE, Cameron M, Chrubasik S. 2009. A systematic review on the effectiveness of willow bark for musculoskeletal pain. Phytother Res 23: 897-900.

Vlachojannis JE, Cameron M, Chrubasik S. 2010a. Medicinal use of potato-derived products : a systematic review. Phytother Res 24: 159-62.

Vlachojannis JE, Cameron M, Chrubasik S. 2010b. A systematic review on the Sambucus fructi effect and efficacy profiles. Phytother Res 24: 1-8.

Wu X, Gu L, Prior RL, McKay S. 2004. Characterization of anthocyanins and proanthocyanins in some cultivars of Ribes, Aronia, and Sambucus and their antioxidant capacity. J Agric Food Chem 52:7846-56.

Yaneva MP, Botushanova AD, Grigorov LA, Kokov JL, Todorova EP, Krachanova MG. 2002. Evaluation of the immunomodulatory activity of Aronia in combination with apple (Plovdiv) 44:22-5. 
Zafra-Stone S, Yasmin T, Bagchi M, Chatterjee A, Vinson JA, Bagchi D. 2007. Berry

anthocyanins as novel antioxidants in human health and disease prevention. Mol Nutr Food

Res 51:675-83.

Zheng W, Wang SY. 2003. Oxygen radical absorbing capacity of phenolics in blueberries, cranberries, chokeberries, and lingonberries. 
23

\section{Ackknowledgement}

The authors sincerely thank Andrew Black / Bristol for his valuable suggestions during the preparation of the manuscript. 